\title{
Low Copy Number and Limited Variability of Proviral DNA in Alveolar Macrophages from HIV-1-Infected Patients: Evidence for Genetic Differences in HIV-1 between Lung and Blood Macrophage Populations
}

\author{
Koh Nakata, ${ }^{* \dagger}$ Michael Weiden,* Timothy Harkin,* David Ho, ${ }^{\dagger}$ \\ and William N. Rom* \\ *Division of Pulmonary and Critical Care Medicine, and Bellevue Chest \\ Service, New York University Medical Center, New York, New York, \\ U.S.A. ${ }^{\dagger}$ Aaron Diamond AIDS Research Center, New York, New York, U.S.A.
}

\begin{abstract}
Background: We investigated the human immunodeficiency virus (HIV) proviral DNA sequence and copy number in alveolar macrophages (AM) and peripheral blood monocytes (PBM) from 10 HIV-positive patients without any active concurrent pulmonary disease to understand the nature of HIV-1 infection in vivo in the lung microenvironment.

Materials and Methods: The 10 seropositive patients without active pulmonary disease were selected based on chest roentegenography and pathological/cytological tests of bronchoalveolar (BAL) fluid. In order to determine accurate proviral copy numbers, AM and PBM were isolated to 99 and $94 \%$ purity, respectively, and quantitative polymerase chain reaction (PCR), with a sensitivity to detect three copies of HIV proviral DNA per $10^{5}$ cells, was applied. For analysis of genetic variation in HIV-1, PCR-amplified HIV-1 DNA from AM and PBM of five patients were subcloned and 2-12 clones from each sample underwent DNA sequence analysis of HIV-1 gp120 V3-V5. Heteroduplex mobility assays were performed to confirm the results of the sequence analysis.
\end{abstract}

Results: The proviral copy number in AM or PBM were less than 20 copies $/ 10^{5}$ cells in all patients, and five patients had less than the detection limit. There was no significant difference in HIV copy number between AM and PBM. No correlation was found between PBM/AM HIV copy number and $\mathrm{CD}^{+}$lymphocyte count in the peripheral blood. Sequence analysis revealed that the mean intrapatient genetic similarity in AM was $97.5 \pm$ $0.18 \%(n=107)$, which was significantly higher than that in PBM $(96.2 \pm 0.26 \%(n=94), p<0.001)$, suggesting that variability of HIV-1 DNA in AM was relatively limited. Divergence occurred when AM derived HIV-1 sequence was compared with PBM derived sequence from the same patient $(95.8 \pm 0.17 \%(n=$ 223) $p<0.001$ ). Phylogenetic analysis of DNA sequence demonstrated complete separation of HIV lineages from lung and blood in four of five patients.

Conclusions: The results suggest that HIV-1 infection in $\mathrm{AM}$ is restricted in vivo with low viral burden and homogenous genotype. We propose that the pulmonary microenvironment may limit the extent of HIV-1 infection.

\section{INTRODUCTION}

The alveolar macrophage (AM) is the predominant defender against environmental pathogens in the lower respiratory tract, yet over 62,000

Address correspondence and reprint requests to: William $\mathrm{N}$. Rom, Division of Pulmonary \& Critical Care Medicine, New York University Medical Center, 550 First Avenue, New York, NY 10016, U.S.A. opportunistic infections per year in acquired immunodeficiency syndrome (AIDS) patients in the United States occur predominantly affecting the lung (1). As $\mathrm{CD}^{+}{ }^{+} \mathrm{T}$ cells fall to very low levels in advanced AIDS, there is no observed concomitant decrease in AM (2), but the risk for pulmonary opportunistic infections increases markedly consistent with an altered functional status of these cells (3-7). Several reports have described 
the AM as chronically harboring human immunodeficiency virus (HIV)-1 DNA in vivo $(8,9)$, and viral production is possibly stimulated by pulmonary inflammation (10).

$\mathrm{AM}$ and peripheral blood monocytes (PBM) belong to a macrophage lineage and are ultimately derived from the same origin, granulocyte-macrophage colony-forming unit (CFUGM) in the bone marrow (11). Macrophages have been considered to be a major target of HIV-1 infection, because most clinical isolates from any stage of the disease are macrophage tropic (12), which appears to be closely associated with the pathogenesis of HIV-1 infection (13). Actually, microglia, brain macrophages $(14,15)$, and macrophages in lymph nodes (16) have been shown to harbor a high copy number of provirus and are producing virions. There is increasing evidence that the tissue-specific microenvironment is important for HIV-I infection of these macrophages in vivo. For example, endothelial cells in brain from AIDS patients with encephalitis are frequently found to be infected with HIV-1 and possibly transmit to microglia and brain macrophages $(17,18)$. Moreover, brain endothelial cells from Simian Immunodeficiency Virus (SIV)-infected monkeys express ELAM-1, an adhesion molecule which may interact with blood monocytes to facilitate their infiltration to the brain (19). Once microglia or brain macrophages are infected, astroglia may stimulate and maintain HIV production through inflammatory cytokines (20). Similarly, lymph node endothelial cells express HIV-I RNA in patients with lymphadenopathy syndrome $(21,22)$, and follicular dendritic cells in patient lymph nodes associate with HIV-1 extracellularly and transmit them to macrophages (16).

On the other hand, the mechanism for HIV infection to $\mathrm{AM}$ in vivo is unclear. $\mathrm{AM}$ can be productively infected by HIV-1 in vitro to the same extent as cultured PBM derived macrophages (23), but the viral load in vivo is estimated to be very low $(24,25)$ and the infection is latent. It is possible that AM are infected with HIV-1 in the pulmonary parenchyma (26), but our and other's recent data suggest that the alveolar microenvironment may contain low levels of HIV-l and thus, AM escape from the infection locally (10). Moreover, many bioactive materials in lung epithelial lining fluid such as IgG, IgA, or surfactant proteins may inhibit HIV infection in a manner similar to that in saliva (27).

Only rare PBM have detectable HIV-1 DNA, and no viral replication has been clearly demonstrated in vivo within these cells $(28,29)$. Distinct from AM, freshly isolated PBM are relatively resistant to HIV-1 infection in vitro, probably due to a defect in viral entry, although PBM increase their susceptibility to productive infection after several days' incubation (23). Thus, PBM seem to be protected from massive infection in vivo, although they are continuously exposed to infectious plasma virus in any stage of disease (30).

One way to elucidate the mechanism for HIV- 1 infection in a particular tissue is to investigate viral sequence variation which is influenced by selective pressure exerted by the tissuespecific microenvironment and not simply a reflection of the intrinsic mutation rate. Namely, sequence heterogeneity may alter cell-specific tropism (31), replication kinetics (32), cytopathic activity (33), and responses to neutralizing antibodies $(34,35)$. The external envelope gp1 20 exhibits extensive heterogeneity in single isolates (36) or between serial isolates from individual patients (37). Extensive studies on env gene sequence analysis between brain and blood (38) or spleen and brain (39) demonstrates heterogeneous sequence distribution between different tissues, suggesting that there might be tissue specific selection pressures.

To elucidate the effect of the pulmonary microenvironment on HIV-1 infection to AM, we purified $A M$ and $P B M$ from 10 seropositive patients without pulmonary complications to compare the accurate proviral copy number and envelope genotype between them. Of critical importance was identifying individuals with normal chest radiographs and excluding other pathogens from the bronchoalveolar lavage fluid because their presence not only stimulates the recruitment of other inflammatory cells to the lung but could also potentially alter the HIV-1 replication rate $(40,41)$ and thus influence the quasi species present. In contrast to circulating $\mathrm{CD}^{+}{ }^{+} \mathrm{T}$ cells, which are reported to harbor relatively high copy numbers of HIV-1 DNA (42), we found that both AM and PBM have a very low copy number even in patients with advanced disease. When the envelope sequence was compared between AM and PBM from five patients, tissue-specific compartmentalization was clearly observed in four patients in both nucleotide and amino acid sequences. Interestingly, the HIV-1 genotype in AM appeared more homogenous than that in PBM in four of five patients studied. These data demonstrate highly restricted HIV-1 species in AM compared with PBM consistent 
with the concept of the AM residing in a protected microenvironment.

\section{MATERIALS AND METHODS Study Population}

Human subjects approval was obtained from NYU Medical Center and Bellevue Hospital Center. Ten HIV-1-infected individuals who were free of respiratory symptoms volunteered for the study including bronchoalveolar lavage. The mean age was $39 \pm 3$ years, and the mean peripheral blood $\mathrm{CD}^{+}$cell count was $145 \pm 68 /$ $\mathrm{mm}^{3}$, with a median of 50 and a range of 3-622/ $\mathrm{mm}^{3}$. All subjects had a normal posterioranterior and lateral chest $\mathrm{X}$-ray, and physical examination. Culture of bronchoalveolar lavage (BAL) fluid for bacteria, fungi, and Mycobacterium tuberculosis was negative for all individuals.

\section{Bronchoalveolar Lavage}

BAL was performed under local anesthesia with $2 \%$ lidocaine and midazolam. Briefly, a flexible fiberoptic bronchoscope (1T 20 D; Olympus, Tokyo, Japan) was inserted into a segmental bronchus of the middle lobe. Three $50-\mathrm{ml}$ aliquots of sterile saline were instilled through a lavage channel and immediately aspirated. Retrieved saline was pooled, placed on ice, filtered through a sterile cell strainer (Becton-Dickinson Co., Mountain View, CA, U.S.A.), collected in a polypropylene tube, and centrifuged at $1000 \mathrm{rpm}$ for $10 \mathrm{~min}$. The supernatant was stored at $-70^{\circ} \mathrm{C}$. The cell pellet was washed twice with cold Hanks' Balanced Salt Solution and resuspended in RPMI 1640 in $10 \%$ fetal calf serum. The number of cells was counted by a hematocytometer and cell differentials were made with a modified Wright-Giemsa stain (Diff-Quick; Fisher Scientific, Pittsburgh, PA, U.S.A.).

\section{Purification of Monocytes and Alveolar Macrophages}

Peripheral blood mononuclear cells (PBMC) were obtained from blood cells by FicollHypaque sedimentation and buffy coats were washed in phosphate-buffered saline (PBS) $\times 4$. PBMC or BAL cells were suspended in RPMI 1640 with $10 \%$ FCS and placed in $35-\mathrm{mm}$ polystyrene plates (Miles Laboratories Inc., Naperville, IL, U.S.A.). The plates were coated with human $\mathrm{AB}$ serum at $4^{\circ} \mathrm{C}$ overnight, and cells were incubated for $40 \mathrm{~min}$ at $37^{\circ} \mathrm{C}$. The plates were washed with PBS $\times 3$, and the adherent cells were removed by gentle scraping with a plastic cell scraper, washed, and resuspended in RPMI. To purify monocytes or AM, the adherent cell suspension was incubated at $4^{\circ} \mathrm{C}$ with antiCD2 and anti-CD19 immuno-magnetic beads (Dynal, Oslo, Norway) at a ratio of 40:1 beads to target cells. After $30 \mathrm{~min}$, the magnetic beads and contaminating lymphocytes were removed with a magnet and the step was repeated. The resultant cells were defined as monocytes or AM by morphology and nonspecific esterase staining with purity of $94.5 \pm 1.2 \%$ and $99.0 \pm 0.2 \%$, respectively.

\section{Quantitative Polymerase Chain Reaction}

A $10-\mu l$ aliquot of cells $\left(10^{7} / \mathrm{ml}\right)$ in PBS was placed into a polymerase chain reaction (PCR) tube (MicroAmp Reaction Tube; Perkin Elmer, NJ, U.S.A.). DNA extraction was performed by adding $2.5 \mu \mathrm{l}$ of $5 \times$ TPK buffer $(50 \mathrm{mM} \mathrm{KCl}, 50$ $\mathrm{mM}$ Tris- $\mathrm{HCl}, \mathrm{pH} 8.3,7.5 \mathrm{mM} \mathrm{MgCl}_{2}, 2.5 \%$ Tween $20,2.5 \%$ Nonidet $-40,500 \mu \mathrm{g} / \mathrm{ml}$ proteinase $\mathrm{K}$ ) and incubated at $55^{\circ} \mathrm{C}$ for $1 \mathrm{hr}$. The DNA was incubated at $95^{\circ} \mathrm{C}$ for $10 \mathrm{~min}$ to inactivate the proteinase K. For HIV-DNA standards, we used the ACH-2 cell line (Dr. Melissa Pope, Rockefeller University), which is reported to have a single copy of provirus per cell. Standards were prepared by diluting known numbers of $\mathrm{ACH}-2$ cells into HIV free THP-1 cells (ATCC) at $4^{\circ} \mathrm{C}$.

The PCR was carried out as described by Go et al. (42). Briefly, SK39-HIV gag primers were end labeled by incubating with T4 polynucleotide kinase $2 \mathrm{U}$ and ${ }^{32} \mathrm{P}$-ATP in kinase reaction buffer for $1 \mathrm{hr}$ at $37^{\circ} \mathrm{C}$, heat inactivated at $65^{\circ} \mathrm{C}$ for $10 \mathrm{~min}$, and purified on G25 spin column. Each reaction contained $10 \mu \mathrm{l}$ of sample, $0.5 \mu \mathrm{l}$ of Taq polymerase (Perkin Elmer), $10 \mu \mathrm{l}$ of $10 \times$ PCR buffer (Perkin Elmer), 100 ng of SK 38, $100 \mathrm{ng}$ of SK39 containing $5 \times 10^{6} \mathrm{cpm}$ of labeled primer, and $0.25 \mathrm{mM}$ of each of the four dNTPs. The primer sequences were: SK38 5'-ATAATC CACCTATCCCAGTAGGAGAAAT- $3^{\prime}$ and SK39 5'TTTGGTCCTTGTCTTATGTCCAGAATGC- ${ }^{\prime}$.

The PCR was performed for 25 cycles (denaturation $91^{\circ} \mathrm{C}$ for $1 \mathrm{~min}$ and annealing and extension at $63^{\circ} \mathrm{C}$ for $2 \mathrm{~min}$ ). To determine the number of copies of HIV present in the amplified product of each reaction, $5 \mu \mathrm{l}$ of amplified products were electrophoretically separated on a $12.5 \%$ nondenaturing polyacrylamide gel. The 
gel was dried and applied to Betagen (Intelli Genetics, Mountain View, CA, U.S.A.), to detect the radioactivity of each $\mathrm{PCR}$ amplicon.

In Patients C, F, G, and I with HIV-1 DNA $<3$ copies $/ 10^{5}$ cells, $10^{6}$ cells were incubated with TPK buffer, phenol:chloroform extracted, ethanol precipitated, and underwent PCR as described above. The copy number was semiquantitatively estimated using autoradiography comparing standard HIV-1 DNA with 0, 10, 25, and 100 copies.

\section{Nested PCR for Amplification of the Envelope Gene}

DNA was extracted from $2 \times 10^{6}$ purified AM or PBM which contained at least $20 \mathrm{HIV}-1$ proviral DNA copies, extracted with phenol-chloroform, ethanol precipitated, and resuspended in $50 \mu \mathrm{l}$ of deionized water. The PCR was performed in 100 $\mu \mathrm{l}$ of reaction mixture containing $2.0 \mathrm{mM} \mathrm{MgCl}$, $50 \mathrm{mM} \mathrm{KCl}, 10 \mathrm{mM}$ Tris- $\mathrm{HCl}$ (pH 8.3), $20 \mu \mathrm{M}$ of each dNTP, $0.5 \mu \mathrm{M}$ each outer oligonucleotide primer pair, and 2.5 units of Taq polymerase (Perkin Elmer). The reactions were performed in Perkin-Elmer Cetus Model 9600 thermocycler programmed for 35 cycles (denaturation at $95^{\circ} \mathrm{C}$ for $1 \mathrm{~min}$, annealing at $55^{\circ} \mathrm{C}$ for $1 \mathrm{~min}$, and extension at $72^{\circ} \mathrm{C}$ for $1.75 \mathrm{~min}$ ). A final extension at $72^{\circ} \mathrm{C}$ for $10 \mathrm{~min}$ was added to the last cycle. A $5-\mu \mathrm{l}$ aliquot was reamplified in a $100-\mu \mathrm{l}$ reaction mix containing $0.5 \mu \mathrm{M}$ each inner oligonucleotide primer pair using the same cycle profile as above. The nested primer sequences were: outer, AS1, 5'-CCAATTCCCATACATTAT TGT-3' (6847 of NL4-3), AS2, 5'-ATAGTGCTTC CTGCTGCTCCCAAGAACC-3' (7803 of NL4-3), inner, AS4, 5'-GTTGGATCCCAGTCTAGCAGAA GAAGA-3' (6994 of NL4-3), AS3, 5'-ACTTCTA GAATTGTCCCTCAT-3' (7633 of NL4-3).

\section{Molecular Cloning and Sequencing}

The nested PCR products of approximately $600-$ $650 \mathrm{bp}$ were resolved by electrophoresis on a $0.8 \%$ agarose gel. The correct DNA fragment was excised from the gel, applied to a Supec II column (Takara, Otsu, Shiga, Japan), phenol:chloroform extracted, and ethanol precipitated. The purified product was dissolved in water and digested with Bam $\mathrm{Hl}$ and $\mathrm{Xbal}$ in the appropriate buffer at $37^{\circ} \mathrm{C}$ for $4 \mathrm{hr}$. An aliquot of the restricted product was evaluated on $1.0 \%$ agarose gel electrophoresis to screen for any potential restriction sites which would select against a par- ticular variant in the population. The cloning of PCR products was performed using the MI3 Cloning Kit (Boehringer-Mannheim, Indianapolis, IN, U.S.A.). Briefly, the restricted amplicon products were ligated to the Ml3mpls vector digested with the same restriction enzyme set and transfected into JM101 cells. Transfected plaques were color selected using IPTG/Xgal agar plates and amplified in JM101 culture medium for $5 \mathrm{hr}$. Single-strand recombinant Ml 3 clones were recovered from culture supernatants by polyethylene glycol precipitation followed by phenol-chloroform extraction and ethanol precipitation. The clones were sequenced in the forward direction by the dideoxy chain termination method using several sequencing primers, ${ }^{35} \mathrm{~S}$ labeled dATP, and Sequenase version 2.0 (U.S. Biochemical, Cleveland, $\mathrm{OH}$ ) according to the manufacturer's directions. Using this procedure on PCR products from ACH-2 cells, we estimated that the rate of misincorporation in our PCR and cloning to be 1 out of 829 bases.

\section{DNA Heteroduplex Mobility Assay}

To evaluate genetic variability of the HIV-1 envelope sequence from AM or PBM, we performed heteroduplex mobility gel shift assay according to the method described by Delwart et al. (43) with slight modifications. Briefly, we selected a recombinant M13 clone described above in each patient, amplified and labeled with $\alpha^{32} \mathrm{P}$ dATP using PCR in the same manner as the aforementioned nested second round PCR. Labeled envelope clones were mixed with nested PCR products at a 1:330 ratio in annealing buffer (1 $\mathrm{M} \mathrm{NaCl}, 100 \mathrm{mM}$ Tris- $\mathrm{HCl} \mathrm{pH} 7.8,20 \mathrm{mM}$ EDTA), denatured at $95^{\circ} \mathrm{C}$ for $3 \mathrm{~min}$, annealed at $22^{\circ} \mathrm{C}$ for $10 \mathrm{~min}$, and cooled on ice. Mixed PCR amplicon was resolved by $4 \%$ nondenaturing polyacrylamide gel electrophoresis in $1 \times \mathrm{TBE}$ for $4 \mathrm{hr}$. The gel was dried and autoradiographed overnight at room temperature.

\section{Data Analysis}

All nucleotide sequences (approximately 597$654 \mathrm{bp}$ ) from this study were aligned by means of the Multiple Alignment Sequence Editor (MASE) program. The sequences were also compared by the "Clustal V" program and the variation was calculated by the DNADIST program. Phylogenetic tree analyses were carried out by DNASTAR program. Other data were analyzed by Statworks using Macintosh computer (Apple 


\section{HIV-1 DNA STANDARD}
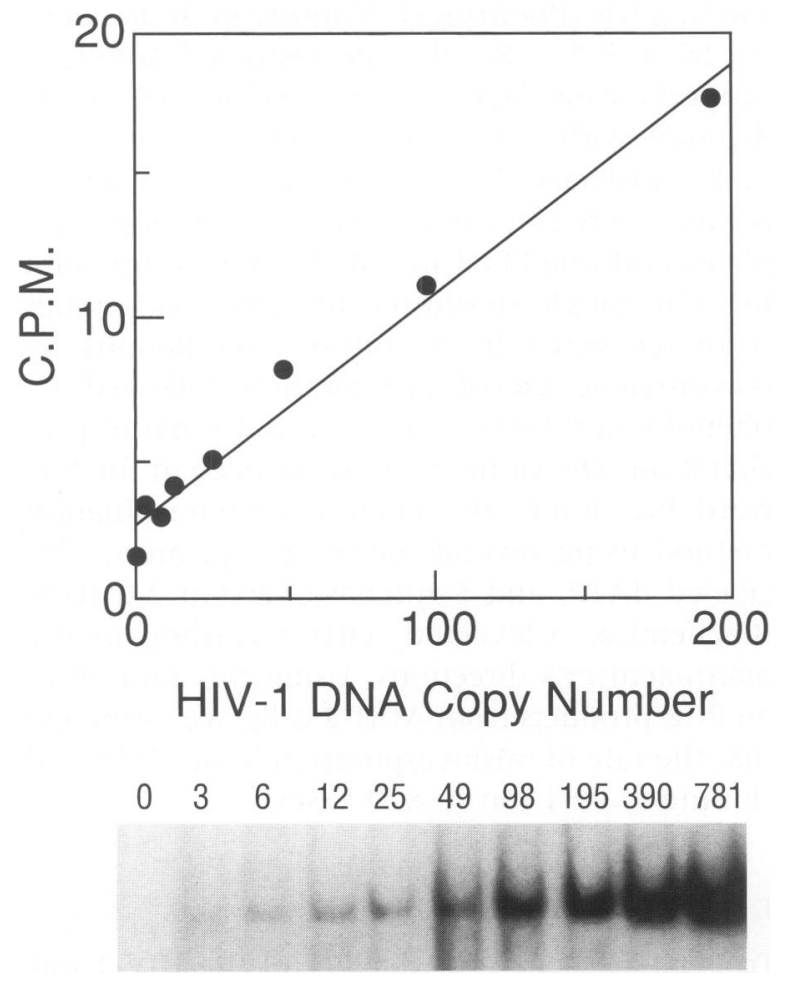

FIG. 1. Quantification of HIV-1 proviral DNA in peripheral blood monocytes, alveolar macrophages, and total bronchoalveolar lavage cells Quantification was performed by the polymerase chain reaction using ${ }^{32} \mathrm{P}$-labeled gag primer (SK39).
Computer, Inc., CA, U.S.A.). Data are expressed as mean \pm SEM. The difference between two groups was evaluated using the Wilcoxon signed rank test. A $p$ value $<0.05$ was considered significant.

\section{RESULTS}

\section{Quantitation of HIV-1 Proviral DNA in AM or PBM}

We performed bronchoalveolar lavage on 10 individuals with no evidence of active pulmonary disease who had a mean age of $38 \pm 3$ years and mean $\mathrm{CD}^{+} / \mathrm{mm}^{3}$ of $141 \pm 69$, and range 3-622 cells/ $\mu$ l. PCR was performed on PBM, AM, unfractionated BAL cells, and PBL with a standard curve of serially diluted ACH-2 cells showing good linearity with a range of 3 to $500 \mathrm{HIV}-1$ proviral DNA copies per $10^{5}$ cells (Fig. 1). Significant provirus $\left(>3\right.$ copies $/ 10^{5}$ cells) was detected in 7 of 9 PBM, 6 of $10 \mathrm{AM}$, and 6 of $8 \mathrm{BAL}$, and 6 of 8 PBL samples studied (Table 1). The proviral copy numbers in PBL were higher than other cell components, especially in Patients $\mathrm{C}$ and $\mathrm{F}$ with 65 and 63 copies, respectively. In contrast, the proviral copy numbers in AM or PBM were remarkably low, being less than 20 copies $/ 10^{5}$ cells in all patients. In Subjects $A$ and $B$ with a high $\mathrm{CD}^{+}$number $\left(>200 / \mathrm{mm}^{3}\right)$ or in Patients $\mathrm{H}$ and

TABLE 1. Quantitation of HIV-1 proviral DNA copy number in AM, PBM, or PBL cells

\begin{tabular}{|c|c|c|c|c|c|}
\hline \multirow[b]{2}{*}{ Patient } & \multirow[b]{2}{*}{ Age } & \multirow[b]{2}{*}{$\mathrm{CD4}^{+}$} & \multicolumn{3}{|c|}{ HIV Copy Number $/ 10^{5}$ Cells } \\
\hline & & & $\mathbf{A M}$ & PBM & PBL \\
\hline A & 49 & 622 & $<3$ & $<3$ & $<3$ \\
\hline B & 26 & 440 & $<3$ & $<3$ & ND \\
\hline $\mathrm{C}$ & 38 & 195 & $1-3^{a}$ & $1-3^{a}$ & 65 \\
\hline D & 39 & 50 & 4 & 4 & $\frac{1-}{3^{a}}$ \\
\hline E & 26 & 50 & 8 & 7 & 5 \\
\hline $\mathrm{F}$ & 44 & 27 & $1-3^{a}$ & 9 & 63 \\
\hline G & 31 & 14 & 3 & $1-3^{a}$ & 5 \\
\hline $\mathrm{H}$ & 39 & 8 & $<3$ & ND & ND \\
\hline I & 53 & 3 & $<3$ & $1-3^{a}$ & 20 \\
\hline $\mathrm{J}$ & 36 & 3 & 20 & 18 & 15 \\
\hline
\end{tabular}

AM, alveolar macrophages; PBM, peripheral blood monocytes; PBL, peripheral blood lymphocytes; ND, none detected. ${ }^{a} \mathrm{HIV}-1$ copy number was more than 10 copies $/ 10^{6}$ cells confirmed by quantitative PCR. 
I with low $\mathrm{CD}^{+}$number $\left(<8 / \mathrm{mm}^{3}\right)$, the HIV-1 copy number was less than 3 copies $/ 10^{5}$ cells. When $10^{6}$ input cells were used, we detected more than 10 copies $/ 10^{6}$ cells for PBM in Subjects $C, G$, and $I$, and for $A M$ in Subjects $C$ and $F$. No difference in the copy number was found among PBM, AM, unfractionated BAL cells, or PBL, although HIV-1 copy number in PBM and AM were correlated $(r=0.86, p<0.01)$. We could not find any correlation between $\mathrm{CD}^{+}$ numbers in the blood and HIV-DNA copy numbers in these three cell populations. Thus, AM from the lung without concurrent disease consistently harbor very low HIV-1 DNA levels which are similar to the level of HIV-1 in PBM from the same subject. These data suggest that HIV-l infection in both AM and PBM is restricted quantitatively in vivo.

\section{HIV-1 Sequences from PBM and AM}

Since we hypothesized that HIV-1 provirus in $\mathrm{AM}$ is in a restricted microenvironment, analogous to microglial cells in the brain, we compared HIV-1 sequences between AM and PBM in Subjects C, E, F, G, and J. We extracted DNA from $2 \times 10^{6}$ cells which contained more than 20 copies of HIV-1 DNA. Nested PCR products coding the V4-V5 region of the envelope gene, 597$654 \mathrm{bp}$, were cloned and sequenced (total 64 clones, 4-12 clones per sample). The large number of different sequences obtained for each sample confirmed sufficient input HIV-1 proviral DNA existed in each sample. Figure 2 shows the alignments of the amino acid translations of the nucleotide sequences. The coding potentials of the V3 and V4-V5 regions of env were maintained in most viral sequences. There was one stop codon in a total of 39,489 bases sequenced. The characteristics of the sequences demonstrated that AM clones appeared to cluster, particularly in Patients C, G, F, and J, but not in Patient $\mathrm{E}$. The difference of sequences between PBM and AM clones were evident with several common amino acid substitutions characteristic for PBM or AM clones in each patient, but we could not find any substitution(s) for PBM or AM clones that was common among five patients.

In general, mutations clustered in the $\mathrm{V} 4$ and $\mathrm{V} 5$ regions. There were significantly more silent mutations in AM (AM 2.4 \pm 0.3 versus PBM 1.7 $\pm 0.3, p<0.01$ ). Other regions including V3 were relatively conserved in each patient between PBM and AM. The top sequons of the V3 loop were also conserved in AM clones, but were somewhat variable in PBM clones, especially in $F$ (GPGG, GPGR, and RPER) and G (GPGK and GPGR). The third amino acid after these top sequons was consistently tyrosine $(\mathrm{Y})$ in all clones studied which is characteristic for macrophage tropic virus (44). The four cysteines that are involved in disulfide bonding and in the formation of the V3 and V4 loops were highly conserved with one substitution in the V3 sequence of a $\mathrm{PBM}$ clone in Subject $\mathrm{F}$. Two $\mathrm{N}$-glycosylation sequons, as defined by a N-X-T or N-X-S sequon, were also conserved in the $\mathrm{V} 3$ region from all five subjects $(96.0 \pm 4.0 \%$ PBM, $96.4 \pm 3.6 \%$ AM, NS), but those in the V4 (four or five sites) or V5 (one site) region showed frequent mutations (V4: $89.0 \pm 4.8 \%$ PBM, $78.8 \pm 9.3 \% \mathrm{AM}$, NS; V5: $61.6 \pm 18.8 \%$ PBM, $57.2 \pm 23.5 \%$ from AM, NS). The mean number of potential N-glycosylation sites in the whole sequence from PBM clones was significantly higher than that from AM clones (PBM: $13.2 \pm 0.21, \mathrm{AM}: 11.9 \pm 0.30$, $p<0.001)$.

Length polymorphism was common in the V4 and V5 region by intrapatient comparison. The number and position of insertion/deletions were relatively conserved within PBM or AM, especially in Patients $C, F$, and $G$ but varied when blood and lung derived sequences were compared. Thus, variability in the $\mathrm{N}$-linked glycosylation sites and length polymorphism in the V4 or V5 region may contribute to conformational and epitope differences between HIV-l virus from PBM and AM.

\section{Intrapatient Sequence Variation}

To assess whether the sequences of the V3-V5 region from AM are representative of the variants within an individual or certain forms may be sequestered in situ, we analyzed intrapatient variation of the nucleotide sequence by comparing two different sequence sets in each subject using the Clustal $\mathrm{V}$ program. The intrapatient genetic distance $(\%)$ data for $A M$ clones was small compared with that for PBM clones in four of five patients (C, F, G, and J) (Table 2). In Subjects $F$ and $J$, the mean distance from PBM was higher than that between PBM and AM, suggesting that some envelope genotypes are intermingled between PBM and AM.

Histograms of intrapatient genetic similarity of all of the sequenced clones demonstrate a high sequence homogeneity in the viral envelope gene from AM $(97.4 \pm 0.16 \%, n=107)$ compared with that from PBM $(96.2 \pm 0.26 \%, n=$ 


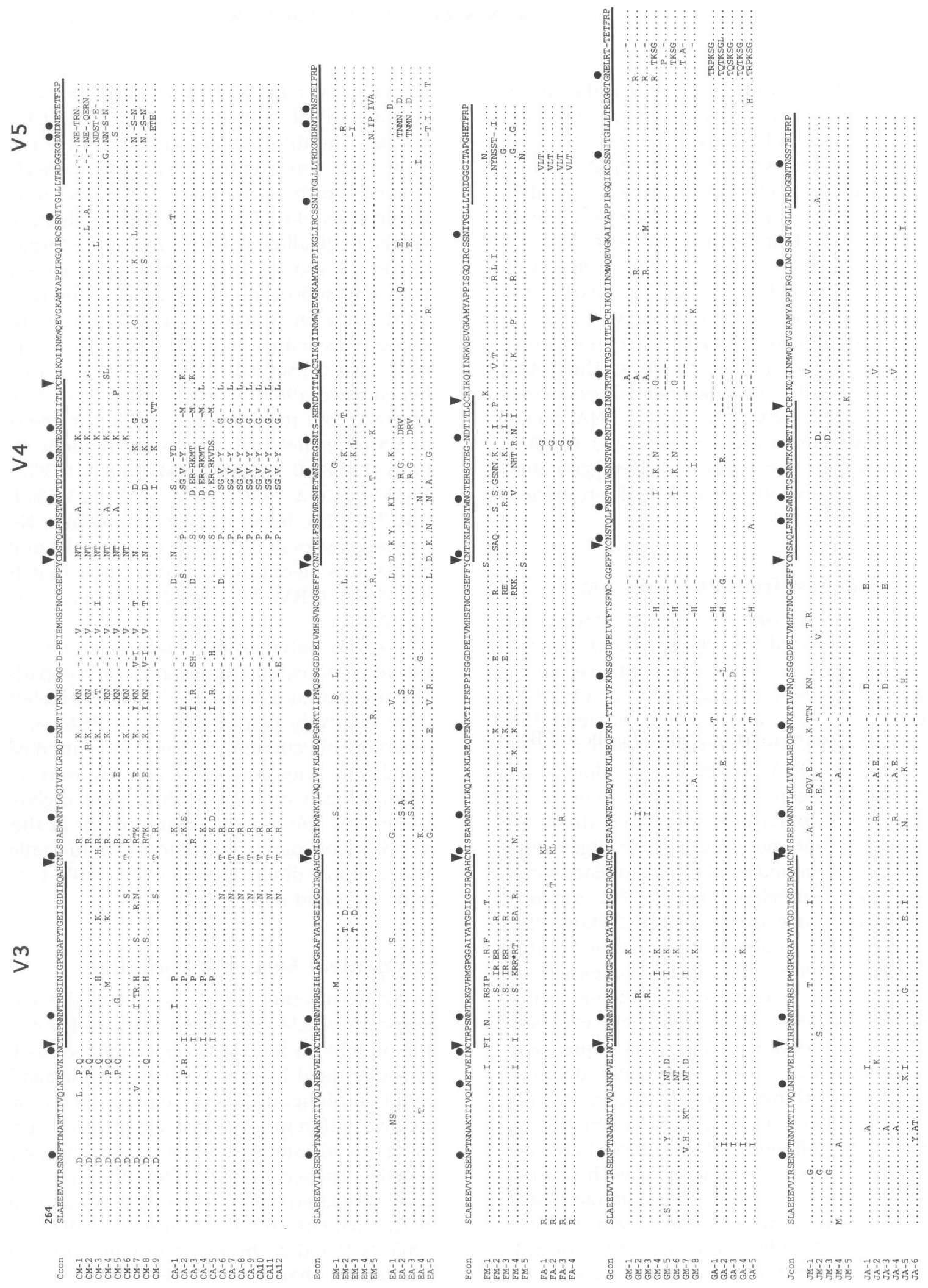

FIG. 2. Amino acid sequence alignments of HIV-1 sequences derived from peripheral blood monocytes and alveolar macrophages

Each sequence represents that obtained from one M13 clone and is aligned with their own consensus sequence. Patients are C, E, F, G, and J. Sequences from monocytes are labeled M and sequences from alveolar macrophages are labeled A. The hyper-variable regions (V3, V4, V5) are underlined. Dots indicate sequence identity; dashes indicate deletions; and an asterisk indicates a stop codon. The four cysteines that are involved in the formation of the V3 and V4 loops are indicated by triangles. Potential N-glycosylation sites are indicated by open circles. 
TABLE 2. Mean intra-patient genetic distance in HIV-l envelope (V3-V5) from AM or PBM

\begin{tabular}{cccc}
\hline & \multicolumn{3}{c}{ Mean Genetic Distance (\%) } \\
\cline { 2 - 4 } Patient & PBM & AM & PBM-AM \\
\hline C & $4.75 \pm 0.29(36)$ & $2.88 \pm 0.25(66)$ & $6.28 \pm 0.20(108)$ \\
E & $1.32 \pm 0.21(10)$ & $3.95 \pm 0.52(10)$ & $3.02 \pm 0.27(25)$ \\
F & $7.75 \pm 1.00(10)$ & $0.83 \pm 0.19(6)$ & $5.51 \pm 0.70(20)$ \\
G & $1.96 \pm 0.15(28)$ & $1.52 \pm 0.19(10)$ & $2.72 \pm 0.90(40)$ \\
J & $3.63 \pm 0.65(10)$ & $1.25 \pm 0.14(15)$ & $3.18 \pm 0.32(30)$ \\
Total & $3.76 \pm 0.26(94)$ & $2.51 \pm 0.18(107)$ & $4.79 \pm 0.17(233)$ \\
\hline
\end{tabular}

Data are expressed as mean \pm SEM. Parentheses indicate numbers of comparison between the two different clones.

94, $p<0.001)$, indicating that the genotype infected in AM was relatively restricted in vivo compared with PBM (Fig. 3). Moreover, the similarity between PBM and AM (95.0 $\pm 0.18 \%$, $n=223$ ) was lower than those in both AM and PBM $(p<0.001)$, suggesting that the nucleotide sequences were compartmentalized in both PBM and AM.

\section{Phylogenetic Analyses of Intrapatient Genetic Distance}

We evaluated the genetic distances among the V3-V5 sequences in each patient using phylogenetic analysis. In three of five data sets, the AMderived viral sequences were tightly clustered relative to the PBM-derived viral sequences and tissue-specific compartmentalization was clear between virus from AM and PBM (Fig. 4, Patients $C, F$, and $G$ ). In the other data sets, AMderived sequences appeared to form two groups in Patient $\mathrm{E}$ and one clone was intermingled in PBM clones in Patient J. The observations were consistent using the phylogenetic tree analysis of amino acid sequence variation (data not shown). These data suggest two divergent pressures imposed upon the HIV-l infection in AM (i.e., one pressure to cluster and another to separate from PBM clones).

\section{DNA Heteroduplex Mobility Assay of V3-V5 from AM and PBM}

Banding patterns of the env gene nested PCR amplicon as seen by DNA heteroduplex mobility
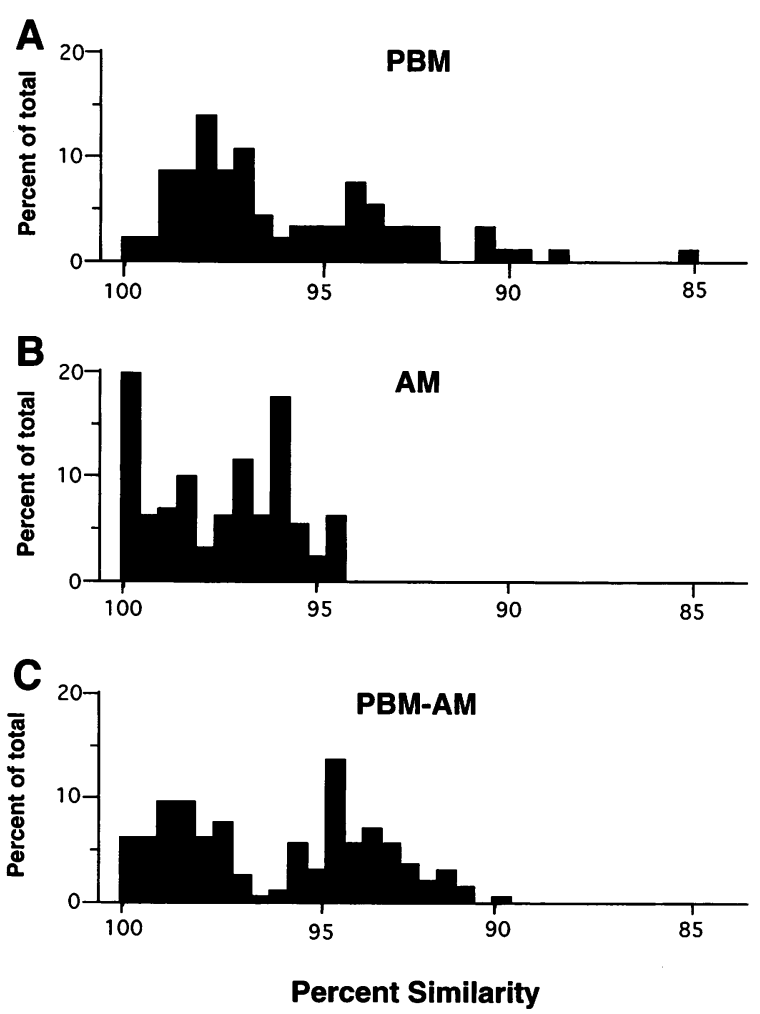

FIG. 3. Intrapatient nucleotide similarity histogram in HIV-1 envelope sequence (V3-V5, 597-654 bp) from five $\mathrm{HIV}^{+}$patients

(A) Intrapatient similarity of sequences in monocytes (PBM, $n=94$ ). (B) Intrapatient similarity of sequences in alveolar macrophages (AM, $n=107$ ). (C) Intrapatient similarity of sequences between monocytes and alveolar macrophages (PBM-AM, $n=223$ ). Each sequence within a set was compared with every other sequence in that set. 


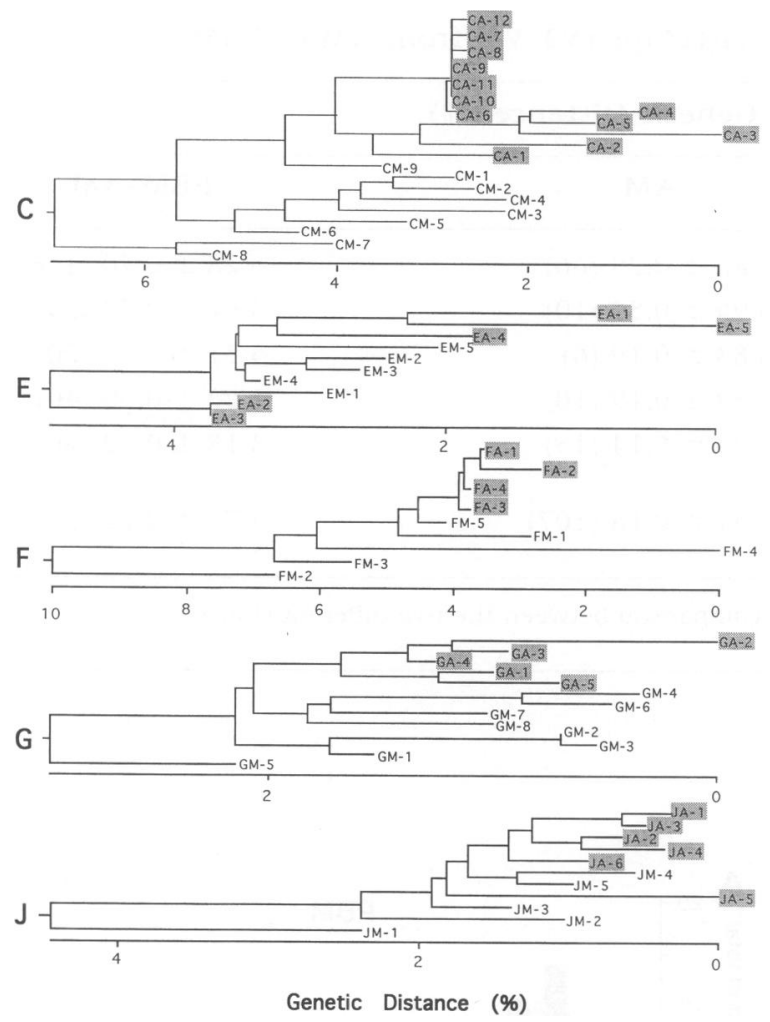

FIG. 4. Phylogenetic trees representing the genetic relationship among V3-V5 sequences obtained from peripheral blood monocytes or alveolar macrophages in five patients (C, E, F, G, and $\mathbf{J}$ )

Each scale means the genetic distance. PBM- and AM-derived clones are labeled $M$ and $A$, respectively. AM-derived clones are also marked by stippled screen.

assay from $\mathrm{PBM}$ or AM matched the genotypes determined by sequence data (Fig. 5). In each patient, AM amplicons tended to cluster to form a major band, whereas banding patterns of PBM amplicons were more complicated and dispersed. The banding pattern of $\mathrm{AM}$ amplicons from $\mathrm{Pa}$ tient $\mathrm{C}$ with a relatively higher $\mathrm{CD}^{+}{ }^{+}$number was clearly distinct from that of each PBM amplicon, suggesting that AM and PBM harbor genetically different virus in this patient. In Patient $\mathrm{E}$, the binding pattern from PBM was more complex than AM; an AM cluster had similar mobility to a PBM cluster. In Patients F, G, and J with low $\mathrm{CD}^{+}$numbers, AM clustered remarkably to form a strong band which had a similar mobility to a major band of the PBM amplicon. On the other hand, the banding pattern of PBM amplicon in Patients $F$ and $G$ but not $J$ showed relatively high variability. Thus, heteroduplex mo- bility assay supported the analyses by sequence variation: homogeneous sequence in $\mathrm{AM}$ clones and tissue-specific compartmentalization between PBM and AM.

\section{DISCUSSION}

In this study, we evaluated the proviral load and genetic variation of HIV-1 in AM and PBM from patients without pulmonary complications. We also tried to elucidate the mechanism for viral transmission and dissemination in these macrophages in the steady state. For this purpose, we selected seropositive subjects without pulmonary complications based on chest roentgenography and pathological/cytological tests of BAL fluid. To determine accurate proviral copy numbers, we purified AM and PBM to 99 and $94 \%$ purity, respectively, and applied a quantitative PCR with the sensitivity to detect 3 copies $/ 10^{5}$ cells. For analysis of genetic variation in HIV-1, we examined the latter half of the envelope gene, which is known to be the most critical region for cell tropism (31). Moreover, we performed heteroduplex mobility assays to confirm the results of sequence analysis.

Our data indicated that HIV-1 proviral copy number in both AM and PBM is very low, even in patients with low $\mathrm{CD}^{+}$numbers. The difference in gp 120 genotype between AM and PBM was clearly observed in all patients with complete separation of proviral lineage observed in four of five individuals (C, E, F, and G). DNA sequence variability was relatively limited in $A M$ compared with PBM. These results suggest that HIV-1 infection in AM is restricted in vivo with little virus detectable and homogeneous gp 120 genotype. We suggest that the pulmonary microenvironment in the absence of inflammation may limit the extent of HIV infection.

Despite the fact that macrophage tropic virus is predominant in clinical isolates from any stage of HIV-1 infection (12), little is known about the accurate viral load in tissue macrophages from various organs. Our data indicate that both AM and PBM do not always harbor HIV-1, even in some patients with advanced AIDS and, if any, the viral load is very low with $0-20$ copies $/ 10^{5}$ cells (detectable in 6 of 10 subjects for AM and 7 of 9 subjects for PBM). Consistent with our data, Sierra-Madero et al. demonstrated that proviral DNA is undetectable or low in both AM and PBM from asymptomatic subjects, but increased in AM from AIDS patients (24). In contrast, Clarke 


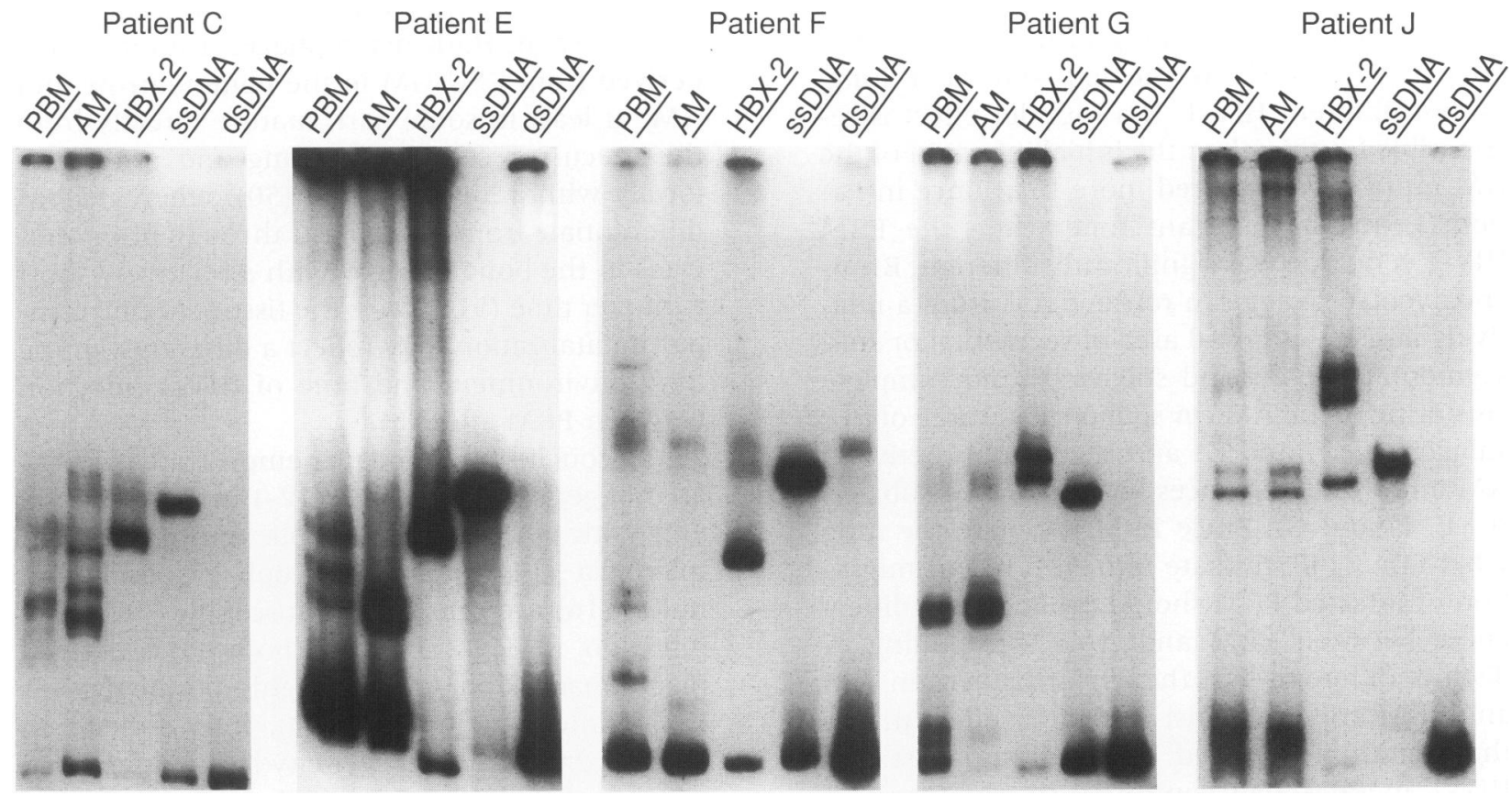

FIG. 5. DNA heteroduplex mobility gel-shift analysis of V3-V5 sequences from monocytes (PBM) and alveolar macrophages (AM) within the same patient

Heteroduplexes were formed by mixing PCR amplicon from HIV-1 infected PBM, AM, or HXB-2 clone with ${ }^{32} \mathrm{P}$ labeled PCR amplicon from one representative clone of the same patient. Patients shown are C, E, F, G, and J. The source of DNA hybridizes with the patient's clone is noted above the lane. ssDNA was the denatured patient clone that was not allowed to reanneal and dsDNA was not denatured.

et al. reported that proviral DNA was found in AM of $47 \%$ of patients tested (9). These findings suggest that AM and PBM are not necessarily reservoirs of latent infection, especially in asymptomatic subjects. Our present data indicate that the proviral copy number in AM and PBM are not significantly different, suggesting that tissuespecific variation in macrophage proviral load between lung and blood is uncommon.

Sequence analysis of the HIV-1 envelope gene in AM and PBM from five AIDS patients revealed that the genotype was different between the two macrophage populations. The mean intrapatient genetic distance of env sequences between AM and PBM was significantly higher than those within AM or PBM. This tendency was clearly observed in Patients C, F, and G. In Patient E, phylogenetic tree analysis of AM clones showed two clusters different from PBM clones; analysis by genetic distance of the sequences showed equivalent divergence in both $\mathrm{AM}$ and PBM. This discrepancy in Patient $\mathrm{E}$ is probably due to a high variability in both $A M$ and PBM; consequently, cloning and additional sequence analysis may clarify this observation. In
Patient $\mathrm{J}$, the sequences were remarkably homogeneous in both AM and PBM and phylogenetic tree analysis suggests an intermingling of the $A M$ genotype with that from PBM. Patient $J$ was free from pulmonary complications, but had far advanced disease with a positive blood culture for Mycobacterium avium-intracellulare and had the highest proviral load of any patient studied. Thus, mycobacteremia may promote the entry of infected monocytes into the lung (45). At the amino acid sequence level, we could not find any common sequence motifs in either AM or PBM. However, the pattern of amino acid substitutions involving $\mathrm{N}$-acetyl glycosylation sites and the sites of deletions/additions were distinct between AM and PBM, especially for Patients C, F, and G.

The difference in env genotype between $A M$ and $P B M$ is possibly due to a founder effect which may distinguish the HIV-l genotype among AM samples from different parts of the lung. For example, the env genotypes in different tissue fragments from an infected spleen were reported to be nonhomogeneous (46). We observed two groups of HIV-l genotypes in AM from Patient $E$, each of which was different from 
the PBM genotype. It is therefore likely that in other patients, AM residing in different pulmonary regions such as the left and right lung, harbor different HIV-1. If a founder effect is responsible for this, then the initial infection of the AM must have occurred more than once in $\mathrm{Pa}$ tient $\mathrm{E}$ and at a distant time when the PBM HIV-1 genotype was significantly different. Bronchoalveolar lavage can retrieve AM from a relatively large anatomical area of segmental or subsegmental regions and still we found complete clustering of the AM env sequence in three of five subjects (C, F, and $G$ ) and segregation between $A M$ and PBM sequences in four of five subjects (C, E, F, and G). Since PBM populate the lung where they differentiate into $A M$, recent migration of infected PBM should produce few differences between PBM and AM. Our finding of distinct differences in the env sequences in AM and PBM argues against a founder effect unless the migration occurred in the distant past and HIV-1 in PBM had continued to replicate and mutate whereas virus in AM remained latent.

A relatively high genetic homogeneity in AM may also support the tissue specific compartmentalization. In four of five subjects analyzed (C, F, $G$, and $J$ ), this tendency was clearly observed compared with PBM. In spite of a high degree of genetic variability in HIV-1 infection, a homogeneous genotype has been demonstrated in blood during primary infection (47) and brain (48). In general, the homogeneity results from a low inoculum or selection among the variants in response to immunologic pressure, alterations in cell tropism, and replication efficiency. Low inoculum of viral burden in the lung, especially in alveolar spaces, may explain the homogeneous $e n v$ sequence in AM. However, a recent quantitative study revealed that free HIV-1 RNA copy number is not so low in BAL fluid compared with plasma level (40). Moreover, the low inoculum does not clearly explain the difference of homogeneity in env sequence variability between AM and PBM, because our present data showed that the viral load was similar between these two macrophage populations. Therefore, the selection by interaction of tissue and virus is a more likely explanation for the homogeneity.

A characteristic environment in the lung such as SIgA, cytotoxic lymphocytes (49) and surfactant proteins may play some role in the selection of AM specific HIV-1 sequences. Also, virus tropism may alter the efficiency of entry or replication of virus in the two different macrophages. Moreover, AM and PBM are distinct in the differentiation pathway, maturation level, and life span. Both macrophages are ultimately derived from CFU-GM in the bone marrow, but $\mathrm{AM}$, at least in some part, mature directly from the precursor cells in the lung and proliferate locally with a long life span (50), whereas PBM differentiate from monoblasts through promonocytes in the bone marrow with a relatively short turnover time (51). Thus, the tissue specific compartmentalization may reflect a difference in the local environment and time of HIV-1 infection between PBM and AM.

In conclusion, our data demonstrate that $\mathrm{AM}$ are not generous hosts for HIV-1 in vivo. It is still enigmatic why other tissue macrophages such as microglia $(14,15)$ and macrophages in lymph nodes (16) are much more susceptible to HIV-1 infection in vivo. Because both PBM-derived macrophages and $A M$ are highly permissive for HIV-1 infection in vitro (23), it is difficult to explain the viral heterogeneity based on the cell tropism of HIV, especially as tissue macrophages are heterogeneous in surface phenotype, function, and morphology. It seems more logical to think that the tissue-specific microenvironment is likely to influence HIV-1 infection in macrophages. Analogous to HIV-l infection in the brain or lymph nodes, further study should be focussed on the interaction between HIV-l and pulmonary microenvironments including capillary endothelial cells and alveolar surfactant.

\section{ACKNOWLEDGMENTS}

We thank Drs. Lin Qi Zhang, Daniel S Nam, Ruth Connor, and Alexandra Spira for assistance, and Ms. Wendy Chen for preparation of figures. We also thank Mrs. Setsuko Ida for valuable technical information. We acknowledge grant support from the NYU Center for AIDS Research (CFAR), GCRC M01 RR00096, AI 35233, HL 51494, and Parker B. Francis Fellowship to MW.

\section{REFERENCES}

1. Farizo KM, Buehler JW, Chamberland ME. (1992) Spectrum of disease in persons with human immunodeficiency virus infection in the United States. J.A.M.A. 267: 1798-1805.

2. Agostini C, Trentin L, Zambello R, et al. (1992) Release of granulocyte-macrophage colony-stimulating factor by alveolar macro- 
phages in the lung of HIV-1-infected patients. J. Immunol. 149: 3379-3385.

3. Koziel H, Kruskal BA, Ezekowitz RA, Rose RM. (1993) HIV impairs alveolar macrophage mannose receptor function against Pneumocystis carinii. Chest 103(Suppl): 111112.

4. Twigg HL, Iwamoto GK, Soliman DM. (1992) Role of cytokines in alveolar macrophage accessory cell function in HIV-infected individuals. J. Immunol. 149: 1462-1469.

5. Trentin L, Garbisa S, Zambello R, et al. (1992) Spontaneous production of interleukin- 6 by alveolar macrophages from human immunodeficiency virus type l-infected patients. J. Infect. Dis. 166: 731-737.

6. Israel-Biet D, Cadranel J, Beldjord K, Andrieu JM, Jeffrey A, Even P. (1991) Tumor necrosis factor production in HIV-seropositive subjects. J. Immunol. 147: 490-494.

7. Twigg HL, Lipscomb MF, Yoffe B, Barbaro DJ, Weissler JC. (1989) Enhanced Accessory cell function by alveolar macrophages from patients infected with the human immunodeficiency virus. Am. J. Respir. Cell Mol. Biol. 1: 391-400.

8. Plata FF, Garcia-Pons A, Ryter F, et al. (1990) HIV-1 infection of lung alveolar fibrobrasts and macrophages in humans. AIDS Res. Hum. Retrovir. 6: 979-986.

9. Clarke JR, Krishnan V, Benet J, Mitchell D, Jefferies DJ. (1990) Detection of HIV-1 in human lung macrophages using the polymerase chain reaction. AIDS 4: 1133-1136.

10. Lebargy F, Branellec A, Deforges L, Bignon J, Bernaudin JF. (1994) HIV-1 in human alveolar macrophages from infected patients is latent in vivo but replicates after in vitro stimulation. Am. J. Respir. Cell Mol. Biol. 10: 72-78.

11. Civin CI, Strauss LC, Brovall C, Fackler MJ, Shwartz JF, Shaper JH. (1984) Antigenic analysis of hematopoiesis. J. Immunol. 133: 157-165.

12. Cloyd MW, Moore BE. (1990) Spectrum of biological properties of human immunodeficiency virus (HIV-1) isolates. Virology 174: 103-116.

13. Mosier DE, Gulizia RJ, Maclsaac PD, Torbett BE, Levy JA. (1993) Rapid loss of $\mathrm{CD}^{+} \mathrm{T}$ cells in human-PBL-SCID mice by noncytopathic HIV isolates. Science 260: 689-692.

14. Sharer LR. (1992) Pathology of HIV-1 infection of the central nervous system. J. Neuropathol. Exp. Neurol. 51: 3-11.
15. Michaels J, Sharer LR, Epstein LG. (1988) Human immunodeficiency virus type 1 (HIV-1) infection of the nervous system. Immunol. Rev. 1: 71-104.

16. Embreston J, Zupancic M, Ribas JL, et al. (1993) Massive covert infection of helper T lymphocytes and macrophages by HIV during the incubation period of AIDS. Nature 362 (6418): 292-293.

17. Wiley CA, Schrier RD, Nelson JA, Lampert PW, Oldstone MBA. (1986) Cellular localization of human immunodeficiency virus infection within the brains of acquired immune deficiency syndrome patients. Proc. Natl. Acad. Sci. U.S.A. 83: 7089-7093.

18. Pumarola-Sune T, Navia BA, Cordon-Cardo C, Cho ES, Price RW. (1987) HIV antigen in the brains of patients with the AIDS dementia complex. Ann. Neurol. 21: 490-496.

19. Sasseville VG, Newman W, Brodie SJ, Hesterberg P, Pauley D, Ringler DJ. (1994) Monocyte adhesion to endothelium in simian immunodeficiency virus-induced AIDS encephalitis is mediated by vascular cell adhesion molecule-1/a4bl integrin interactions. Am. J. Pathol. 144: 27-40.

20. Epstein LG, Gendelman HE. (1993) Human Immunodeficiency virus type 1 infection of the nervous system: Pathogenetic mechanisms. Ann. Neurol. 33(5): 429-436.

21. Schuurman HJ, Krone WJA, Broekhuizen R, Goudsmit J. (1988) Expression of RNA and antigens of human immunodeficiency virus type-1 (HIV-1) in lymph nodes from HIV-1 infected individuals. Am. J. Pathol. 133: $516-$ 524.

22. Baroni CD, Pezzella F, Pezzella $M$, et al. (1988) Expression of HIV in lymph node cells of LAS patients. Immunohistology, in situ hybridization, and identification of target cells. Am. J. Pathol. 133: 498-506.

23. Rich EA, Chen ISY, Zack JA, Leonard ML, O'Brien WA. (1992) Increased susceptibility of differentiated mononuclear phagocytes to productive infection with human immunodeficiency virus-1 (HIV-1). J. Clin. Invest. 89: $176-183$.

24. Sierra-Madero JG, Toossi Z, Hom DL, Finegan CK, Hoenig E, Rich EA. (1994) Relationship between load of virus in alveolar macrophages from human immunodeficiency virus type 1 -infected persons, production of cytokines, and clinical status. J. Infect. Dis. 169: 18-27.

25. Landay AL, Schade SZ, Takefman DM, et al. 
(1993) Detection of HIV-1 provirus in bronchoalveolar lavage cells by polymerase chain reaction. J. AIDS 6: 171-175.

26. Itescu S, Simonelli PF, Winchester RJ, Ginsberg HS. (1994) Human immunodeficiency virus type 1 strains in the lungs of infected individuals evolve independently from those in the peripheral blood and are highly conserved in the C-terminal region of the envelope V3 loop. Proc. Natl. Acad. Sci. U.S.A. 91: $11378-11382$.

27. Archibald DW, Cole GA. (1990) In vitro inhibition of HIV infectivity by human salivas. AIDS Res. Hum. Retroviruses 6: 1425-1432.

28. Ho DD, Rota TR, Hirsh MS. (1986) Infection of monocyte/macrophages by human T lymphotropic virus type III. J. Clin. Invest. 77: 1712-1714.

29. McElrath MJ, Steinman RM, Cohn ZA. (1991) Latent HIV-1 infection in enriched populations of blood monocytes and $\mathrm{T}$ cells from seropositive patients. J. Clin. Invest. 87: 27-30.

30. Piatak MJ, Saag MS, Yang LC, et al. (1993) High levels of HIV-1 in plasma during all stages of infection determined by competitive PCR. Science 259: 1749-1754.

31. Shioda T, Lavy JA, Cheng-Mayer C. (1991) Macrophage and $\mathrm{T}$ cell-line tropisms of HIV- 1 are determined by specific regions of the envelope gp-120 gene. Nature (Lond) 349: 167-169.

32. Fenyo EM, Morfeldt-Manson L, Chiodi F, et al. (1988) Distinct replicative and cytopathic characteristics of human immunodeficiency virus isolates. $J$. Virol. 62: 4414-4419.

33. Tersmette $M$, Gruters RA, de Wolf $F$, et al. (1989) Evidence for a role of virulent human immunodeficiency virus (HIV) variants in the pathogenesis of acquired immunodeficiency syndrome: studies on sequencial HIV isolates. J. Virol. 63: 2118-2125.

34. Albert J, Abrahamsson B, Nagy K, et al. (1990) Rapid development of isolate-specific neutralizing antibodies after primary HIV-1 infection and consequent emergence of virus variants which resist neutralization by autologus sera. AIDS 4: 107-1 12.

35. Nara PL, Smit L, Dunlop N, et al. (1990) Emergence of viruses resistant to neutralization by V3-specific antibodies in experimental human immunodeficiency virus type 1 IIIB infection of chimpanzees. J. Virol. 64: 3779-3791.

36. Fisher AG, Ensoli B, Looney D, et al. (1988)
Biologically diverse molecular variants within a single HIV-1 isolate. Nature (Lond) 334: 444-447.

37. Meyerhans A, Cheynier R, Albert J, et al. (1989) Temporal fluctuations in HIV quasispecies in vivo are not reflected by sequential HIV isolations. Cell 58: 901-910.

38. Pang S, Vinters HV, Akashi T, O'Brien WA, Chen ISY. (1991) HIV-1 Env sequence variation in brain tissue of patients with AIDSRelated neurologic disease. J. AIDS 4: 10821092.

39. Epstein LG, Kuiken C, Blumberg BM, et al. (1991) HIV-1 V3 domain variation in brain and spleen of children with AIDS: Tissuespecific evolution within host-determined quasispecies. Virology 180: 583-590.

40. Lu W, Israel-Biet D. (1993) Virion concentration in bronchoalveolar lavage fluids of HIV infected patients. (Letter) Lancet 31: 342.

41. Zhang $\mathrm{Y}$, Nakata $\mathrm{K}$, Weiden $\mathrm{M}$, Rom WN. (1995) Mycobacterium tuberculosis enhances HIV-1 replication by transcriptional activation at the long terminal repeat. J. Clin. Invest. 95: 2324-2331.

42. Go AS, Zack JA, Arrigo SJ, Chen ISY. (1988) Quantitative polymerase chain reaction. Techniques HIV Res. pp. 113-119.

43. Delwart EL, Shpaer EG, Louwagie J, et al. (1993) Genetic Relationships determined by a DNA heteroduplex mobility assay: analysis of HIV-1 env genes. Science 262: 1257-1261.

44. Westervelt $P$, Trowbridge BD, Epstein LG, et al. (1992) Macrophage tropism determinants of human immunodeficiency virus type 1 in vivo. J. Virol. 66: 2577-2582.

45. Velo GP, Spector WG. (1973) The origin and turnover of alveolar macrophages in experimental pneumonia. J. Pathol. 109: 7-19.

46. Delassas S, Cheynier R, Wain-Hobson S. (1992) Nonhomogenious distribution of human immunodeficiency virus type 1 proviruses in the spleen. J. Virol. 66: 5642-5645.

47. Zhu T, Mo H, Wang N, et al. (1993) Genotypic and phenotypic characterization of HIV- 1 in patients with primary infection. Science 261: 1179-1181.

48. Korber BTM, Kunstman KJ, Paterson BK, McEvilly MM, Levy R, Wolinsky SM. (1994) Genetic differences between blood and brain derived viral sequences from HIV-1 infected patients. Evidence of conserved elements in the $\mathrm{V} 3$ region of the envelope protein of brain-derived sequences. J. Virol. 68: 74677481 . 
49. Autran B, Mayaud CM, Raphael M, et al. (1988) Evidence for a cytotoxic T-lymphocytes alveolitis in human immunodeficiency virus-infected patients. AIDS 2: 179-183.

50. Nakata K. (1994) Proliferation of alveolar macrophages. In: Takishima T (ed). Basic and Clinical Aspects of Pulmonary Fibrosis. CRC Press, Boca Raton, pp. 133-145.

51. Van Furth R. (1989) Origin and turnover of monocytes and macrophages. Curr. Topics Pathol. 79(6): 125.

Contributed by L. Philipson on July 25, 1995. 